\title{
O NOVO ESTATUTO DA VÍTIMA EM PORTUGAL: SUJEITO OU ENFEITE DO PROCESSO PENAL PORTUGUÊS?
}

\section{${ }^{1}$ Maria João Guia}

\section{RESUMO}

O presente artigo visa enquadrar e refletir sobre o papel da vítima no processo penal, procurando-se indagar se a vítima adquiriu, com as recentes alterações ao Código do Processo penal português (CPP) e com a introdução da Lei no 130/2015 de 4 de Setembro, o estatuto de sujeito processual ou se, pelo contrário esta Lei apenas foi promulgada por obrigação de transposição de diretivas europeias, sem que tenha introduzido um verdadeiro poder processual interventivo à vítima.

Palavras-chave: Transposição de Diretiva Europeia, Direitos das Vítimas de Crimes, Estatuto

\section{EL NUEVO ESTATUTO DE LA VÍCTIMA EN PORTUGAL: ASUNTO O ADORNO PROCESO PENAL PORTUGUÉS?}

\section{RESUMEN}

Este artículo tiene como objetivo enmarcar y reflexionar sobre el papel de las víctimas en los procesos penales, tratando de averiguar si la víctima ha adquirido, con los cambios recientes al Código del Penal Procedimiento portugués (CPP) y la introducción de la Ley N 130/2015 de 4 septiembre, el estado del sujeto procesal o si por el contrario esta ley sólo fue promulgada por la transposición de directivas obligación Europea sin que él ha hecho una víctima intervenir facultad procesal real.

Palabras-claves: Transposición de la Directiva Europea, Derechos de las Víctimas de la Delincuencia, Estatuto

\footnotetext{
1 Doutora em Direito, Justiça e Cidadania pela Universidade de Coimbra - UC, Lisboa (Portugal). É Investigadora Associada do Centro de Direitos Humanos da Faculdade de Direito da Universidade de Coimbra - UC, Lisboa (Portugal).

E-mail: maria.joao.guia@ij.uc.pt
} 


\section{INTRODUÇÃO}

Os direitos das vítimas de crimes têm vindo a ser relegados, ao longo dos anos, para um plano secundário. A Decisão Quadro 2001/220/JAI do Conselho, de 15 de Março, visava chamar a atenção para $\mathrm{a}(\mathrm{s})$ lacuna(s) ${ }^{1}$ existente(s) na ótica legislativa europeia respeitante ao papel da vítima, que suscitava preocupação da comunidade jurídica desde os anos $70^{2}$. Na generalidade, os Estados-Membros da União Europeia não encontravam no papel da vítima uma prioridade de intervenção legislativa, pelo que esta Decisão-Quadro marcou um momento assinalável nesta matéria ${ }^{3}$, tendo-se procurado reconhecer e respeitar o estatuto da vítima, com direitos e interesses legítimos no âmbito do processo penal ${ }^{4}$. O objetivo era o de implementar o direito de audição e de apresentação de provas, devendo cada Estado-membro diligenciar no sentido de adotar as medidas consideradas necessárias, bem como pugnar pelo direito de a vítima receber informações relevantes para a proteção dos seus direitos (entre os quais direito a receber apoio, aconselhamento jurídico, apoio judiciário e indemnização). A legislação existente e adotada, neste contexto, foi considerada ineficaz ${ }^{5}$, fazendo-se menção expressa à transposição da Decisão-Quadro de 2001 que não previa uma série de aspetos (ou cuja transposição apenas ocorreu parcialmente ${ }^{6}$ ) que implicavam graves lesões aos direitos das vítimas. Estas viam, assim, os agressores serem condenados por força do investimento penal feito

\footnotetext{
${ }^{1}$ Apesar de, já em 29 de Novembro de 1985, a ONU ter publicado na sua resolução nº 40/34 um documento pioneiro nesta matéria: "Declaração dos Princípios Básicos de Justiça Relativos às Vítimas da Criminalidade e Abuso de Poder", aceita-se que a Decisão-Quadro 2001/220/JAI tenha sido o primeiro documento europeu que marcou uma viragem na reflexão sobre este assunto (Pwemberton e Groenhuijsen, 2011).

${ }^{2}$ Vide a exposição de motivos da proposta de lei 343/XII/4" (GOV) citada em CSM, 2015:9 "O reconhecimento e a consagração legal dos direitos das vítimas têm sido paulatinamente construídos, com maior intensidade nos últimos 40 anos, em particular através da adoção de instrumentos normativos pelas organizações internacionais".

${ }^{3}$ Pemberton, Antony and Groenhuijsen, Marc, Developing Victim's Rights within the European Union: Past, Present and Future (October 21, 2011). Acedido em SSRN: http://ssrn.com/abstract=1947236 or http://dx.doi.org/10.2139/ssrn.1947236 aos 10/11/2015.

${ }^{4}$ Objetivos reforçados no Programa de Estocolmo - "Uma Europa aberta e segura que sirva e proteja os cidadãos", de 2009 e no Tratado de Lisboa (artigo $82^{\circ}$ ).

${ }^{5}$ Vide proposta de lei 343/XII/4a (GOV) de CSM, 2015:4, "Os relatórios de execução sobre a (...) Decisão-

Quadro - de 2004 e 2009 - concluíram que a legislação da União Europeia tinha sido ineficaz para garantir a proteção adequada às vítimas em toda a EU".

${ }^{6} \mathrm{Na}$ comunicação intitulada "Thoughts and hopes for victims' rights in the future", ocorrida no passado dia 14/01/2016, no Seminário IVOR organizado pela APAV, Katazyna Janicka-Pawlowska da Comissão Europeia mencionou que a Bélgica, Irlanda, França, Croácia, Lituânia, Holanda, Áustria, Roménia e Finlândia apenas tinham transposto parcialmente a Diretiva. Contudo, e segundo a mesma, esta comunicação de cada país em nada tem a ver com a efetiva transposição legal e efetivação dos direitos atribuídos às vítimas mas sim às perceções que o próprio país evidencia do que entende ter sido a transposição completa ou parcial dos direito ali previstos. A fase de avaliação ainda não foi iniciada.
} 
a partir da lei criminal, mas mantendo-se as mesmas afastadas da intervenção no processo penal, o que lesava os direitos que eventualmente lhes poderiam assistir ${ }^{7}$. Na generalidade, os direitos das vítimas passaram por três fases distintas: a primeira em que lhes foi concedido o acesso de compensações, assistência e apoio; o segundo que incluía os direitos específicos à informação e o terceiro, o que previa direitos concretos de participar no processo penal (victims protection.eu, 2013: 6). Muitos destes avanços foram conquistas de diferentes movimentos de vítimas de crimes específicos, não funcionando estes como um todo unido, mas de forma independente e pugnando por direitos próprios para cada grupo (vítimas de tráfico de pessoas, de violência doméstica, entre outros).

Portugal, à semelhança de outros Estados-membros, implementou algumas das medidas, promulgando a Lei 112/2009, de 16 de Setembro, o que deu um especial enfoque à proteção das vítimas de violências doméstica ${ }^{8}$, promovendo ou reforçando assim uma hierarquização ${ }^{9}$ em que estas, até ao presente momento, acedem a todos os direitos recomendados pela Decisão-Quadro de 2001, ficando vítimas de outros crimes em posição diametralmente oposta. Acresce que as vítimas de alguns crimes apenas recentemente o passaram a ser. Não se pode olvidar que a escolha de criminalizar é uma decisão política. Um recente exemplo foi este ano legislado por força da promulgação ${ }^{10}$ da Lei

\footnotetext{
${ }^{7} \mathrm{O}$ projeto "Intervict" da APAV demonstrou que muitos dos Estados-membros não implementaram todos os artigos recomendados ou evidenciando sérias lacunas no acesso aos direitos previstos.

${ }^{8}$ No relatório intitulado "Violência contra as mulheres: um inquérito à escala da União Europeia", FRA,

2014, foram feitas entrevistas a 42 mil mulheres nos 28 Estados-membros. De entre as muitas conclusões, destacamos que, desde os 15 anos, uma em cada 10 mulheres foi vítima de algum tipo de violência sexual; uma em cada 20 foi violada; uma em cada 5 sofreu algum tipo de violência física e/ou sexual perpetrada por um parceiro atual ou anterior. Apenas $14 \%$ das mulheres denunciaram as situações.

${ }^{9}$ No âmbito do projeto "Protecting Victims' Rights in the EU: the theory and practice of diversity of
}

treatment during the criminal trial" (JUST/2011/JPEN/AG/2919), coordenado pelo Centre for European Constitutional Law - Themistokles and Dimitris Tsatsos Foundation (www.cecl.gr) e o Institute for Advanced Legal Studies, School of Advanced Study, University of London (www.ials.sas.ac.uk) financiado pela Criminal Justice Programme of the European Union, de que a autora foi relatora por Portugal. A autora organizou um Focus Group no dia 24/05/2013, no CES em Coimbra e que integrou a CPV, a APAV, a PSP, Saúde em Português, a APF, a CIG, a GNR, o INML, o SEF, um Juiz desembargador, um advogado. De acordo com um dos participantes, a Decisão-Quadro 2001/220/JAI foi totalmente transposta para a lei 112/2009 de 16 de Setembro. "If we focus on the spirit that gave way to the construction of this Directive, one of the main ideas was the definition of victim hierarchies and the truth is that the person that drafted this Law no 112/2009 basically picked up the Directive's predecessor, the Framework Decision of 2001, and transposed, almost ipsis verbis, to Law 112/2009 the first third of this European Framework Decision. This decision that encompassed all crime victims was imported to Portugal and applied to domestic violence victims only. Giving the relevance of this issue in our country this positive discrimination can be justified in some aspects but not in all. This intended hierarchy of victims that was initially foreseen in Law no 112/2009 does not make sense, in our opinion, and in practice we will have to transpose these measures to other victims. Doubtlessly, in a series of aspects, and at least in legal terms, domestic violence victims are far more protected than other victims".

10 Segundo Coyle (2008) (e recorrendo ao que foi discutido na $12^{\text {a }}$ Conferência dos Diretores dos Estabelecimentos Prisionais na Europa, que decorreu em novembro de 2002, onde se fez menção à escolha 
83/2015, de 05 de Agosto $^{11}$ ). Não se tendo verificado a eficácia e abrangência desejadas com a transposição desta Diretiva, que não foi uniformemente adotada na pluralidade legislativa dos diferentes Estados-Membros (nem, de resto, em Portugal se estendeu a todas as vítimas), sobretudo no que concerne o contexto do processo penal, o assunto voltou a adquirir relevo na ponderação das áreas prioritárias da União Europeia. ${ }^{12}$, Foi, por isso, publicada a Diretiva 2012/29/EU, de 25 de Outubro desta feita com a força vinculativa da obrigação de ser implementada por todos os Estados-membros até 16 de Novembro de 2015 (cfr. $n^{\circ} 1$, do $\operatorname{art}^{\circ} 27^{\circ}$ da Diretiva 2012/29/EU).

No enquadramento exposto apresentar-se-á no primeiro ponto os direitos principais previstos na Diretiva 2012/29/EU, de 25 de Outubro com especial enfoque nos que se centram sobre a intervenção da vítima no processo penal ${ }^{13}$. De seguida, passar-se-á a refletir sobre a Lei 130/2015, de 4 de Setembro que transpôs mais recentemente as recomendações para a legislação portuguesa ${ }^{14}$, analisando algumas opiniões do Conselho Superior de Magistratura sobre reflexões que estiveram na base da decisão de implementação de certas recomendações. De recordar que, neste artigo, apenas nos atemos à que se refere ao estatuto jurídico-penal da vítima enquanto sujeito ou participante no processo penal. Em terceiro lugar, discorrer-se-á sobre os sujeitos e participantes processuais existentes no enquadramento jurídico português. Por último

consciente ou inconsciente que os Estados fazem nesta área) há fatores como os Estados Europeus terem decidido criminalizar progressivamente mais comportamentos alongando as penas. "Em larga medida [as prisões] refletem os valores a que cada sociedade adere. Uma sociedade pode optar por ter uma taxa de prisão alta ou baixa e esta escolha reflete-se nos padrões de sentença adotadas pelos juízes. Nos últimos anos, uma série de países europeus, especialmente na Europa Ocidental, decidiu, conscientemente ou por defeito, ter taxas mais altas de encarceramento" (Coyle, 2008:7-8) (Guia, 2015: 300).

${ }^{11}$ Crimes de perseguição, casamento forçado e de mutilação genital feminina, p.p. nos $\operatorname{art}^{\circ} \mathrm{s} 154^{\circ} \mathrm{A}, 154^{\circ} \mathrm{B}$ e $144^{\circ} \mathrm{A}$, respetivamente.

${ }^{12}$ Sobretudo com a adoção da Resolução de 10 de junho de 2011 sobre um roteiro para o reforço dos direitos e da proteção das vítimas, nomeadamente em processo penal (conhecido como o «Roteiro de Budapeste») e da Resolução de 5 de abril de 2011 sobre prioridades e definição de um novo quadro político da União Europeia em matéria de combate à violência contra as mulheres.

${ }^{13}$ Destacamos para o presente artigo o texto apresentado no no 20 do preâmbulo da Diretiva 2012/29/EU: "O papel atribuído às vítimas no sistema de justiça penal e a possibilidade de as vítimas participarem ativamente no processo penal variam de Estado-Membro para Estado-Membro em função do respetivo sistema nacional e são determinados por um ou vários dos seguintes critérios: saber se o sistema nacional prevê um estatuto jurídico de parte no processo penal, se a vítima tem a obrigação legal de participar ativamente no processo penal ou é chamada a participar ativamente nele, por exemplo, como testemunha, e/ou se a vítima tem o direito, segundo a legislação nacional, de participar ativamente no processo penal e procura fazê-lo, caso o sistema nacional não confira à vítima o estatuto jurídico de parte no processo penal. Cabe aos Estados-Membros determinar qual ou quais desses critérios se aplicam para determinar o âmbito dos direitos previstos na presente diretiva, caso existam referências ao papel da vítima no sistema de justiça penal pertinente."

${ }^{14}$ Escolhemos para este artigo tratar apenas a questão da ponderação do estatuto adotado para a vítima na legislação portuguesa (enquanto sujeito ou mero participante processual) pelo que apenas faremos algumas referências a outros dos direitos que a mesma adquiriu ou cujas recomendações se encontram publicadas na Diretiva. 
apresentar-se-á uma reflexão crítica sobre o novo estatuto da vítima enquanto possível "sujeito" do processo penal, referindo-nos aos direitos e deveres que lhe assistem enquanto tal e comparativamente aos outros sujeitos processuais. Faremos ainda uma análise crítica quanto à possível assunção do papel da vítima enquanto "mero participante", figurando neste papel por força de um dispositivo legal europeu vinculativo, sem ter adotado a dignidade processual que potencialmente terá estado na base da criação do seu estatuto e colidindo com a existência de outros sujeitos/participantes processuais já constantes na lei portuguesa.

\section{A DIRETIVA 2012/29/EU, DE 25 DE OUTUBRO - DIREITOS, APOIO E PROTEÇÃO DAS VÍTIMAS DA CRIMINALIDADE}

Para além das muitas recomendações emanadas pela Diretiva 2012/29/EU (dividida em 6 capítulos temáticos: disposições gerais, prestação de informações e apoio, participação no processo penal, proteção das vítimas e reconhecimento das vítimas com necessidades específicas de proteção, outras disposições, disposições finais), relativas aos direitos das vítimas ${ }^{15}$, (que não iremos aqui tratar), o artigo $2^{\circ}$, relativo às definições, apresenta recomendações sobre o que deverá entender-se por "vítima".

Quanto ao papel que os Estados-membros podem adotar nas legislações nacionais relativos ao papel da vítima ( $\mathrm{n}^{\circ} 20$ do preâmbulo), distinguindo-se estas duas recomendações (a da definição de vítima e a do papel assumido pela mesma na legislação de cada Estado-membro), foi deixado livremente ao critério de cada Estado-membro a tomada de decisão quanto ao nível de intervenção que o mesmo pode assumir em cada legislação nacional (enquanto lesado, testemunha, assistente ou não assumindo qualquer papel formalmente interventivo ${ }^{16}$ ). Foi, no entanto, recomendado, e em salvaguarda do

\footnotetext{
15 Não posso, no entanto, deixar de fazer menção a outros diplomas legais onde muitos dos direitos apresentados na Diretiva já se encontravam previstos, ainda que atribuídos a sujeitos/participantes no processo penal ou grupos específicos de vítimas, como é o caso da lei de Proteção de testemunhas (93/99, de 14 de Julho), Criação de um regime de mediação Penal (Lei 21/2007, de 12 de Junho), Regime de concessão de indemnização às vítimas de crimes violentos e de violência doméstica (Lei n. ${ }^{\circ}$ 104/2009, de 14 de Setembro), Lei de estrangeiros ( $\operatorname{art}^{\circ}$ s $109^{\circ}$ a $111^{\circ}$ da lei 23/2007, de 4 de Julho), a regulamentação de concessão de autorização de residência a vítimas de tráfico de pessoas (Decreto-Regulamentar 368/2007, de 5 de Novembro), Lei da Violência doméstica (lei no 112/2009, de 16 de Setembro), entre outros. Para um maior aprofundamento, vide relatório de Portugal sobre a implementação da Diretiva (Guia, 2013) disponível em_http://www.victimsprotection.eu/index.php/2014-05-01-19-31-19/jd/viewcategory/40-ptportugal

${ }^{16}$ Ainda que o Tratado de Funcionamento da União Europeia ( $\left.\operatorname{art}^{\circ} 288^{\circ}\right)$ e o Tribunal de Justiça da União Europeia (caso 96/81 e caso C-361/88) se pronunciem quanto à necessidade de implementação de
} 
princípio da certeza legal, que os estados-membros deveriam estabelecer um critério legal objetivo a nível de cada uma das legislações nacionais, podendo usar como o guia o recomendado no $\mathrm{n}^{\circ} 20$ do preâmbulo ${ }^{17}$. Naturalmente, e tendo em conta as diferenças existentes entre os dispositivos legais de cada Estado-membro no que concerne os sujeitos e os participantes nos processos penais, cada Estado-membro poderia implementar o papel que a vítima iria adquirir formalmente no processo penal tendo em conta essas mesmas diferenças ${ }^{18}$.

Em termos do que a Diretiva 2012/29/EU recomenda, e tendo em conta o que o documento auxiliar para a transposição da Diretiva 2012/29/EU (European Commission, DG Justice, December, 2013) menciona, sobretudo no aqui nos preocupa e que se centra no artigo $11^{\circ}$ ("Direitos no caso de uma decisão de não deduzir acusação"), mais uma vez se destaca a preocupação sobre o papel a assumir pela vítima em termos formais no processo penal, sobretudo quando está em causa um crime "grave" (não havendo especificação na Diretiva do que se entende por crime "grave". Refere-se aqui a possível existência de um acusador privado ou subsidiário em ordenamentos jurídicos de determinados Estados-membros, sendo que, contudo, esta não é a recomendação do mencionado no artigo $11^{\circ}$ uma vez que não é "qualitativamente - da perspetiva dos interesses da vítima - o mesmo do que o recomendado no artigo $11^{\circ}$ ”. Dir-se-ia, para os presentes efeitos, que estaríamos perante a figura do sujeito processual penal português do assistente. E assim a recomendação conclui haver um dever de ponderação dos aspetos positivos e negativos da potencial necessidade de a vítima se constituir assistente para poder intervir formalmente no processo penal ${ }^{19}$.

verdadeiras medidas e não apenas de práticas administrativas ou circulares (EUROPEAN COMMISSION, DG JUSTICE, Dezembro 2013: 6).

${ }^{17}$ European Commission, DG Justice December 2013, "DG Justice Guidance Document related to the transposition and implementation of Directive 2012/29/EU of the European Parliament and of the Council of 25 October 2012 establishing minimum standards on the rights, support and protection of victims of crime, and replacing Council Framework Decision 2001/220/JHA".

${ }^{18}$ Vide European Commission, DG Justice, december 2013:4 "Since the formal role of victims in criminal proceeding varies significantly between Member States, the implementation of these Articles will be different to some extent and influence the particular procedural consequences and the extent of the rights of the victims set out in this Directive".

19 "Becoming a private prosecutor may have its advantages but also constitutes an additional burden on the victim in terms of time, costs, etc. Therefore it is questionable if this burden may be mitigated by the provision of free legal aid and other assistance" (ECDGJustice, 2013: 31). 


\section{A TRANSPOSIÇÃO DA DIRETIVA PARA A LEI 130/2015, DE 4 DE SETEMBRO - ALTERAÇÕES PRINCIPAIS NO CPP}

$\mathrm{O}$ preâmbulo do código do processo penal $^{20}$ refere-se à excecionalidade das medidas portuguesas tomadas relativamente a decisões do legislador que colocou Portugal na vanguarda e como pioneiro relativamente a outros Estados-membros. Um dos exemplos avançados é precisamente o da "vítima-assistente" ${ }^{21}$ ", referindo-se este preâmbulo ao reforço das competências deste sujeito processual penal de assistente ${ }^{22}$.

Mas antes de entrarmos no debate sobre os sujeitos ou participantes no processo penal, iremos apresentar o que foi vertido da Diretiva 2012/29/EU para o processo penal português, focando-nos na escolha sobre o papel atribuído à vítima e as explicações aventadas para tal.

O Conselho Superior de Magistratura pronunciou-se sobre este assunto $^{23}$ referindo-se à ausência, durante muito tempo, deste novo "ator", a vítima, estando plasmados os sistemas jurídicos, em vários países europeus, construídos à volta do arguido e dos seus direitos. É reconhecido como um "grande desafio para os EstadosMembros (...) o de determinar claramente o papel da vítima em todas as fases do processo penal", verificando-se, em vários Estados-membros, uma sobreposição e pouca clarificação no que respeita medidas adotadas para com testemunhas ou "grupos vulneráveis específicos". A dificuldade da "definição de um estatuto homogéneo para as vítimas de crimes" é, com efeito, resultante de as mesmas irem assumindo "as vestes de assistentes ou demandantes civis" ou a intervirem como meras "denunciantes e testemunhas". Os regimes jurídicos que delimitam cada um destes atores é, por isso, diferente (a uns é reconhecido o papel de assistente ao passo que a outros o de meros participantes), podendo ou não intervir de forma mais direta em certos atos processuais ou não, consoante a veste de que são revestidas. A proposta de lei manteve os conceitos de assistente e de demandante civil, autonomizando, no entanto o conceito de vítima. E por forma a fazer face à obrigatoriedade da transposição da diretiva, foram introduzidas alterações na lei que visavam um acesso mais abrangente ${ }^{24}$ (também temporalmente) ao

\footnotetext{
${ }^{20}$ Decreto-Lei no $78 / 87$, de 17 de Fevereiro.

21 "Paradigmático a este respeito é o que se passa com o estatuto da vítima-assistente, que nos singulariza claramente no contexto do direito comparado e por cujo modelo começam agora a orientar-se os movimentos de reforma de muitos países, sob o impulso das mais recentes investigações criminológicovitimológicas" (nº 4 do preâmbulo do Decreto-Lei nº 78/87, de 17 de Fevereiro, 2015:4).

22 "Da mesma postura relevam, em geral, todas as disposições que, como implicações do sistema acusatório,

visam realizar, na medida do possível, a reclamada 'igualdade de armas' entre a acusação e a defesa. O mesmo poderá ainda afirmar-se a propósito do reforço da consistência do estatuto do assistente, com a intenção manifesta de consolidar o papel de um dos protagonistas no campo da conflitualidade real".
} 

23Vide "Parecer sobre a Proposta de Lei n $^{\circ}$ 343/XII/4a (GOV), datado de 03/07/2015, elaborado peloadjunto do G
AVPM, Juiz de Direito, Dr. Carlos Gabriel Donoso Castelo Branco.

${ }^{24}$ Foram alterados os artigos $68^{\circ}, 212^{\circ}, 246^{\circ}, 247^{\circ}, 292^{\circ}$ e $495^{\circ}$ do Decreto-Lei ${ }^{\circ}$ 78/87, de 17 de Fevereiro. estatuto de assistente a que a vítima poderia apelar em certas condições estatuídas. Assim,

o $\operatorname{art}^{\circ} 68^{\circ}$, al. c) prevê agora que a vítima possa decidir constitui-se assistente, e assim poder recorrer da decisão, "no prazo para interposição de recurso da sentença". No que respeita ao $\operatorname{art}^{\circ} 212^{\circ}, \mathrm{n}^{\circ} 4^{\circ}$, (e também ao previsto na alteração do $\operatorname{art}^{\circ} 292^{\circ}$ e $495^{\circ}$ ) abrese a possibilidade de a vítima (ainda que não revestida do papel de assistente) “deve[r](...) ser $(\ldots)$ ouvida $(\ldots)$, sempre que necessário" $\left(212^{\circ}\right)$, "quando o julgar necessário e sempre que estes o solicitarem" (292) e "sempre que necessário" $\left(495^{\circ}\right)$. O artigo $246^{\circ}$ introduziu a obrigatoriedade de uso de intérprete ${ }^{25}$, sempre que o denunciante não conheça a língua portuguesa (e salvaguardando-se o disposto nos $\operatorname{art}^{\circ} \mathrm{s} 92^{\circ}$ e $93^{\circ}$ ). A alteração introduzida no $\operatorname{art}^{\circ} 247^{\circ} n^{\circ} 7$ refere-se à obrigatoriedade da entrega de um certificado de denúncia, contendo a descrição dos factos essenciais do crime em causa (com recurso a intérprete, se tal se revelar necessário), bem como, no n 3, a informação a prestar "ao ofendido" sobre a indemnização "a vítimas de crimes violentos".

Por último, julgamos digno de relevo mencionar que o estatuto da vítima se consagrou em 29 artigos que se encontram em legislação avulsa (lei 130/2015, de 4 de Setembro) e com 16 menções no $\mathrm{CPP}^{26}$, não sendo completamente evidente o motivo que levou a tal escolha (os direitos e artigos referentes aos ofendidos ${ }^{27}$ estão previstos no texto do CPP, tal como os do lesado ${ }^{28}$ e os do assistente ${ }^{29}$ ). A questão da delimitação dos sujeitos e participantes no processo penal português levanta, por isso, algumas questões, sobretudo se questionarmos qual então o papel previsto e atribuído à vítima enquanto sujeito ou participante no processo penal.

\footnotetext{
${ }^{25}$ Não se vislumbra, de resto, que pudesse ser registada denúncia sem que a informação fosse percetível, pelo que, ainda que agora esteja formalmente prevista esta obrigatoriedade, acreditamos que esse fosse já o procedimento tomado (sobretudo tendo em conta os $\operatorname{art}^{\circ} \mathrm{s} 92^{\circ} \mathrm{e} 93^{\circ}$ do $\mathrm{CPP}$ ).

${ }^{26}$ No CPP, com a designação vítima, encontrámos 16 menções ( $\operatorname{art}^{\circ} 1^{\circ}, 67^{\circ}-\mathrm{A}, 82^{\circ}-\mathrm{A}, 88^{\circ}, 89^{\circ}, 141^{\circ}, 187^{\circ}$, $\left.194^{\circ}, 212^{\circ}, 247^{\circ}, 257^{\circ}, 271^{\circ}, 281^{\circ}, 292^{\circ}, 385^{\circ}, 495^{\circ}\right)$.

${ }^{27}$ Em pesquisa autónoma feita pelo termo ofendido, encontrámos menções no CPP a $17 \operatorname{artigos,~os~art~}^{\circ} \mathrm{s}$ $23^{\circ}, 30^{\circ}, 39^{\circ}, 49^{\circ}, 50^{\circ}, 68^{\circ}, 86^{\circ}, 89^{\circ}, 138^{\circ}, 200^{\circ}, 215^{\circ}, 217^{\circ}, 243^{\circ}, 247^{\circ}, 271^{\circ}, 283^{\circ}, 383^{\circ}$.

${ }^{28}$ No que respeita o "lesado" encontrámos $18 \operatorname{artigos}\left(\operatorname{art}^{\circ} 30^{\circ}, 72^{\circ}, 74^{\circ}, 75^{\circ}, 76^{\circ}, 77^{\circ}, 80^{\circ}, 81^{\circ}, 83^{\circ}, 89^{\circ}\right.$,

$\left.227^{\circ}, 228^{\circ}, 281^{\circ}, 307^{\circ}, 339^{\circ}, 341^{\circ}, 347^{\circ}, 393^{\circ}\right)$.

${ }^{29}$ Quanto ao termo "assistente" detetámos $115 \operatorname{artigos}\left(n^{\circ} 7^{\circ}, 13^{\circ}, 23^{\circ}, 30^{\circ}, 32^{\circ}, 35^{\circ}, 36^{\circ}, 38^{\circ}, 39^{\circ}, 41^{\circ}, 43^{\circ}\right.$,

$45^{\circ}, 50^{\circ}, 66^{\circ}, 68^{\circ}, 69^{\circ}, 70^{\circ}, 74^{\circ}, 77^{\circ}, 86^{\circ}, 87^{\circ}, 89^{\circ}, 102^{\circ}, 107^{\circ}, 108^{\circ}, 110^{\circ}, 113^{\circ}, 117^{\circ}, 120^{\circ}, 122^{\circ}, 133^{\circ}$, $138^{\circ}, 141^{\circ}, 146^{\circ}, 153^{\circ}, 154^{\circ}, 155^{\circ}, 156^{\circ}, 157^{\circ}, 160^{\circ}$-A, $166^{\circ}, 188^{\circ}, 212^{\circ}, 215^{\circ}, 236^{\circ}, 246^{\circ}, 268^{\circ}, 271^{\circ}, 273^{\circ}$, $276^{\circ}, 288^{\circ}, 278^{\circ}, 281^{\circ}, 283^{\circ}, 284^{\circ}, 285^{\circ}, 287^{\circ}, 289^{\circ}, 292^{\circ}, 294^{\circ}, 297^{\circ}, 302^{\circ}, 303^{\circ}, 307^{\circ}, 309^{\circ}, 311^{\circ}, 313^{\circ}$, $314^{\mathrm{o}}, 315^{\mathrm{o}}, 318^{\mathrm{o}}, 319^{\mathrm{o}}, 330^{\circ}, 331^{\mathrm{o}}, 339^{\circ}, 341^{\circ}, 343^{\circ}, 345^{\circ}, 346^{\circ}, 347^{\circ}, 349^{\circ}, 350^{\circ}, 353^{\circ}, 356^{\circ}, 359^{\circ}, 360^{\circ}$, $363^{\circ}, 371^{\circ}, 374^{\circ}, 376^{\circ}, 377^{\circ}, 378^{\circ}, 384^{\circ}, 387^{\circ}, 388^{\circ}, 389^{\circ}, 390^{\circ}, 391^{\circ}, 392^{\circ}, 401^{\circ}, 407^{\circ}, 415^{\circ}, 421^{\circ}, 437^{\circ}$, $\left.443^{\circ}, 446^{\circ}, 450^{\circ}, 456^{\circ}, 459^{\circ}, 463^{\circ}, 495^{\circ}, 497^{\circ}, 514^{\circ}, 515^{\circ}, 517^{\circ}, 518^{\circ}\right)$.
} 


\section{OS SUJEITOS E PARTICIPANTES DO PROCESSO PENAL PORTUGUÊS - TENTATIVA DE DELIMITAÇÃO DO PAPEL DA VÍTIMA}

Segundo o Código do Processo Penal, o Livro I da Parte I trata "Dos sujeitos do processo", o que revelaria, em abstrato, uma especificação com peso semelhante a todos os sujeitos. Este livro contém 6 partes que supostamente constituiriam os seis sujeitos processuais: os 3 primeiros centrados no agente do crime (parte III - "do arguido e do seu defensor), nos elementos responsáveis pela investigação e acusação (parte II “do ministério público e dos órgãos de polícia criminal”) e nos responsáveis pelas apreciações e decisões judiciais (parte I “do juiz e do tribunal”) e os 3 últimos centrados em quem impende uma lesão de direitos por força de um ato criminoso, subdividindo-se estes, por sua vez, em 3 categorias: a vítima (parte IV), o assistente (parte V) e as partes civis (parte VI). Segundo Figueiredo Dias (1993:8), os sujeitos do processo penal estão hierarquizados na "trindade" dos principais (o tribunal, o ministério público e o arguido), o que explica as menções ao enfoque "arguidocêntrico" (Guia, 2015) e de "estrutura acusatória $^{30 "}$ do processo penal português ${ }^{31}$. Desde logo se verifica, neste sentido, o peso desigual atribuído aos sujeitos processuais de investigação, acusação e decisão em detrimento dos outros três titulares, todos lesados por força da ocorrência de um crime. E entre estes 3 últimos constata-se também uma diferenciação hierárquica que coloca o assistente $^{32}$ no topo das possibilidades de exercício de direitos na qualidade de sujeito processual penal, em detrimento da sobreposição não totalmente clara entre a figura da vítima e do ofendido, deixando-se a figura do lesado numa estreita relação com a parte VI (das partes civis).

Assim, e segundo o estatuído no Código do Processo Penal (al. a), $n^{\circ} 1, \operatorname{art}^{\circ} 68^{\circ}$ ), ofendido será "os titulares dos interesses que a lei especialmente quis proteger com a incriminação, desde que maiores de 16 anos". Lesado será $\left(n^{\circ} 1, \operatorname{art}^{\circ} 74^{\circ}\right)$ "a pessoa que sofreu danos ocasionados pelo crime, ainda que se não tenha constituído ou não possa

\footnotetext{
${ }^{30}$ Figueiredo Dias, 1993:8 e Decreto-lei no 78/87, de 17 de Fevereiro, no 7 do preâmbulo: “a) A primeira nota tem a ver com a estrutura básica do processo. Por apego deliberado a uma das conquistas mais marcantes do progresso civilizacional democrático, e por obediência ao mandamento constitucional, o Código perspectivou um processo de estrutura basicamente acusatória". Vide ainda a exposição de motivos da proposta de lei 343/XII/4a (GOV) citada em CSM, 2015:9, "durante muito tempo a preocupação dominante foi a determinação da sanção aplicável ao criminoso, obnubilando as vítimas e as suas necessidades de proteção".

${ }^{31}$ Opiniões colhidas aos atores institucionais participantes no Focus Group mencionado na nota 9.

${ }^{32}$ Esta questão foi abordada no decurso do Focus Group já mencionado "Why not granting the victim

procedural rights directly, why do we need the image of the assistant? The problem is not the image of the assistant, the problem is the victim of the crime who should be granted rights in the process when she presses charges. And she's not. She has the form of the assistant where a number of people can fit, including the victim. And the victim should have the dignity of standing per se."
} 
constituir-se assistente". Vítima, segundo o $\operatorname{art}^{\circ} 67-\mathrm{A}^{\circ}$, al. a) sub. “i) A pessoa singular que sofreu um dano, nomeadamente um atentado à sua integridade física ou psíquica, um dano emocional ou moral, ou um dano patrimonial, diretamente causado por ação ou omissão, no âmbito da prática de um crime; ii) Os familiares de uma pessoa cuja morte tenha sido diretamente causada por um crime e que tenham sofrido um dano em consequência dessa morte".

Antes de mais, não podemos deixar de chamar a atenção para a desconsideração e falta de atenção do legislador, quer da Diretiva 2012/29/UE, quer da Lei 130/2015, de 4 de Setembro para o facto de apenas se entender como vítima o "familiar" da mesma se esta morrer em consequência de ter sido vítima de um crime. Se porventura essa vítima de crime ficar em coma, paralisada ou viva, mas impedida de falar, deslocar-se, com algum tipo de deficiência, não poder esse familiar beneficiar dos ora aqui plasmados “direitos da vítima" pelo facto de esta não ter falecido (unicamente o podendo fazer se assumir o papel de assistente).

Para além do mais, estas designações levam-nos a acreditar estarmos perante uma sobreposição de atores, especificamente a vítima e o ofendido. Senão vejamos 3 exemplos não totalmente claros em que a vítima e o ofendido se cruzam de forma não totalmente indistinta. O primeiro resulta da análise do $\mathrm{n}^{\circ} 2$ do artigo $271^{\circ}$ (declarações para memória futura) que menciona "No caso de processo por crime contra a liberdade e autodeterminação sexual de menor, procede-se sempre à inquirição do ofendido no decurso do inquérito, desde que a vítima não seja ainda maior".

Não será ainda despicienda a constatação de que 5 dos sujeitos estão titulados pela menção "do" ("Do juiz e do tribunal", parte I, livro I, titulo I, por exemplo), ou "dos" ("Do Ministério Público e dos órgãos de polícia criminal, titulo II), ao passo que apenas o mais recentemente integrado no artigo $67^{\circ}$-A apenas se encontra com a menção "Vítima", sem o devido "Da". Qual a razão que levou a esta omissão: esquecimento? Lapso? Acreditamos que tal possa dever-se ao facto de os seus direitos estarem discriminados em lei autónoma (a Lei 130/2015, de 4 de setembro) e não no código do processo penal (como os dos outros sujeitos/participantes processuais se encontram), o que de imediato se evidencia como uma diferenciação (que pode ser interpretada positiva ou negativamente) relativamente a este novo ator processual.

Mas será a vítima um verdadeiro "sujeito" do processo penal ou mais um "participante" do mesmo? 


\section{OPINIÃO CRÍTICA - SUJEITO OU ENFEITE?}

Mediante tudo o que foi exposto, outra resposta não nos ocorre que não seja a inclusão da vítima no papel de participante e nunca de sujeito processual, pelo facto de ter a mesma que requerer aos sujeitos processuais de pendor acusatório e decisório a assunção da veste de assistente para poder aceder a todos os direitos que a lei lhe confere, em termos da sua participação plena (e prevista na lei) no processo penal.

Temos, assim, que recordar a recomendação do documento de análise da diretiva que mencionava a necessidade de ponderação dos Estados-membros quanto à dilação temporal que levaria a assunção da vítima do papel de assistente e aos custos ${ }^{33}$ que tal revestiria. No entanto, estamos em crer que o legislador preferiu precaver-se de um uso excessivo da figura do assistente, caso o mesmo passasse a ser automaticamente adquirido pela vítima, por ter sido vítima. Assim, razões de índole da celeridade processual e da simplificação de práticas (mencionadas no preâmbulo do CPP) poderão ter pendido na escolha do legislador para impedir um gozo total e pleno de intervenção processual da vítima enquanto sujeito, passando esta apenas a revestir as vestes de participante processual e apenas de sujeito processual, requerendo o estatuto de assistente.

Analisemos, por exemplo o $\mathrm{n}^{\circ} 4$ do artigo $212^{\circ}$ do CPP em que a vítima “deve[r](..) ser (..) ouvida (..), sempre que necessário”. Ora quem decide que é necessário que a mesma seja ouvida? Não nos parece que a vítima, na qualidade de participante processual, sem ter assumido a qualidade de assistente, poderá alegar e vincular a necessidade de ser ouvida, havendo sempre a necessidade de uma decisão superior à da sua qualidade enquanto vítima.

O mesmo se depreende da análise do $\operatorname{art}^{\circ} 292^{\circ}$, em que a vítima será ouvida “quando o [juiz de instrução] julgar necessário e sempre que estes [vítima e arguido] o solicitarem" ( $\left.\mathrm{n}^{\mathrm{o}} 2 \mathrm{do}^{\mathrm{art}}{ }^{\circ} 292^{\circ}\right)$. A vítima pode requerer ser ouvida, mas tal não vincula a obrigatoriedade de se decidir da necessidade de tal, cabendo ao juiz de instrução essa mesma decisão.

\footnotetext{
${ }^{33}$ Este facto foi criticado no decurso do Focus Group já referido "As to the victim and the problem of the assistant the question revolves around the obligation of paying what is asked, since the right of access to justice is provided for in the Portuguese Constitution and the fact is that some people do not have the money to pay for that. It does not work when it should, and this problem needs to be solved. Certain crimes, and the crimes we are addressing here are serious crimes, are public crimes and the Public Prosecutor has a fundamental role in this field, if the victim is not cared for as it should the Law is not to blame as much as the person responsible for the process in hands".
} 
Mais uma vez o $n^{\circ} 2$ do $\operatorname{rt}^{\circ} 495^{\circ}$ e a menção "sempre que necessário" (no 2, do $\operatorname{art}^{\circ} 495^{\circ}$ ) vincula o decisor, e não a vítima, à possibilidade de ser ouvida, mesmo que não se tenha constituído assistente.

No que concerne a sobreposição entre vítima e ofendido, o $\operatorname{art}^{\circ} 247^{\circ} n^{\circ} 7$ referese à obrigatoriedade da entrega de um certificado de denúncia, contendo a descrição dos factos essenciais do crime em causa (com recurso a intérprete, se tal se revelar necessário), bem como, no $\mathrm{n}^{\circ} 3$, a informação a prestar "ao ofendido" sobre a indemnização "a vítimas de crimes violentos”. Encontramos aqui, quase como sinónimos, os dois participantes, ainda que possamos vislumbrar a diferenciação do ofendido, enquanto titular do direito, da vítima, enquanto pessoa atingida pelo crime.

Nos documentos analisados, destacamos ainda a revisão do Conselho Superior de Magistratura, (2015: 12) numa formulação que não nos parece ser a mais percetível. Na apreciação feita à transposição do conceito de vítima $\left(67^{\circ}-\mathrm{A}\right)$, pronuncia-se o CSM referindo "à formulação normativa que tal conduta, mais do que um dever processual consiste num direito deste participante e sujeito processual, aspeto que é evidenciador do novo estatuto reforçado que se preconiza para a 'vítima", o que pressuporia que a vítima teria assumido o papel de sujeito processual. Não se constata, porém, haver no papel da vítima qualquer confirmação de que a mesma assuma o papel de sujeito processual. Não tem o mesmo poder/direitos do que um assistente, apenas a facilidade de poder eventualmente solicitar a apreciação de se revestir desse papel, e de ter direitos e apoios que o Estado lhe faculta, por assumir a condição de vítima. Mas em termos do papel que lhe é conferido no processo penal, não se nos afigura que o mesmo seja atribuível enquanto "sujeito processual".

Ainda no mesmo documento, o que menciona o autor da revisão da proposta da CSM sobre a proposta para a transposição da designação de "criança", valerá para a sobreposição entre ofendido e vítima. Ainda que estejamos alertas de que, por ofendido, se entende "os titulares dos interesse que a lei especialmente quis proteger com a incriminação, desde que maiores de 16 anos" (al.a), $n^{\circ} 1$, $\operatorname{art}^{\circ} 68^{\circ}$ ), julgamos haver uma área de indefinição e de indistinção entre o conceito de ofendido e de vítima (quando a atual lei designa por vítima "a pessoa singular que sofreu um dano (...) diretamente causado (...) no âmbito da prática de um crime" (sub.al. i) da al. a) no 1 , $\operatorname{art}^{\circ} 67^{\circ}$-a) e "os familiares de uma pessoa cuja morte tenha sido diretamente causada por um crime e que tenham sofrido um dano em consequência dessa morte" (sub.al. ii), al. a), artç 67-A). Não são então estes dois conceitos de vítimas também "titulares dos interesses que a lei 
especialmente quis proteger com a incriminação"? O que os distingue objetivamente, para além da possibilidade de haver ofendidos que poderão não ter sido vítimas de crimes e serem, por isso, apenas titulares dos interesses (no caso, por exemplo, de não entrar no conceito de familiar de vítima (previsto na sub.al. ii) quando a mesma, ainda que ofendida gravemente na sua integridade física e sujeita, por exemplo, a incapacidade grave e permanente, mas não morta em consequência do crime? Nestes casos em que não há morte em consequência do crime e a vítima do mesmo ficou, por exemplo, em coma, incapacitada de denunciar/apelar aos seus direitos, contemplados neste novo estatuto da vítima, os familiares em nada poderão integrar-se que não seja o papel de participante no processo penal enquanto ofendidos ou de sujeito processual enquanto assistente (al. d), $\mathrm{n}^{\circ}$ $1^{\circ}, \operatorname{art}^{\circ} 68^{\circ}$ ), mas nunca no papel de vítima e por isso impedidas de beneficiar dos direitos que lhe assistem e que integraram o novo estatuto da vítima. $\mathrm{O}$ ofendido não pode, por isso, ser sempre equiparado à condição de vítima (porque pode ser apenas o titular dos interesses), enquanto que a vítima será sempre integrável na condição de ofendido. Mas nunca nenhum destes participantes tem direto acesso à condição de assistente, tendo sempre que submeter a uma decisão superior (e aqui se acentuam as hierarquias constituídas entre os participantes e sujeitos processuais penais e entre os próprios sujeitos processuais, recordando-se a "trindade" referida por Figueiredo Dias (1993) que tem em si o poder de apreciar um requerimento que permita a assunção desta qualidade). Apenas em circunstâncias formalmente delimitadas "procedimento dependente de acusação particular" (art $\left.50^{\circ} ; \mathrm{n}^{\mathrm{o}} 3, \operatorname{art}^{\circ} 68^{\circ}\right)$, o assistente adquire um papel de relevo de não subordinação do Ministério Público, em que este último apenas acusa depois do assistente o fazer $\left(\operatorname{art}^{\circ} 285^{\circ}\right)$ (sendo que em crimes públicos ou semi-públicos, o papel do assistente não passa de colaborador da entidade principal que é o Ministério Público).

\section{CONCLUSÕES}

Em jeito de conclusão, não podemos deixar de mencionar alguns pontos, em jeito de conclusão.

Primeiro, pelo que já foi exposto, a vítima de um crime, para poder ter plenos direitos processuais em Portugal, tem que se constituir assistente, o que implica o pagamento de uma UC, atualmente $€ 102,00$, valor que nem todos poderão pagar. Não nos é alheio o número de pessoas que na sociedade portuguesa vive atualmente com o salário mínimo nacional (505 euros, em 2015, Pordata), totalizando 12,9\% da população empregada em 2014. Segundo os dados do INE de 2014, 34\% dos portugueses recebe 
menos de 600 euros mensais e $61 \%$ não ultrapassam os 900 euros. Considerando então que Portugal será o quinto país da zona euro onde mais trabalhadores vivem em risco de pobreza (10,5\% da população), bem como o facto de quase ter que se viver de forma indigente para beneficiar da isenção deste pagamento, nem todos os cidadãos vítimas de crime dispõem de meios financeiros suficientes para fazer face a este encargo, para além do que dispõem para as despesas com a sua sobrevivência e encargos mensais.

Segundo aspeto e decorrente do anterior, é duplamente penalizador alguém que tenha sido vítima de um crime ter que pagar uma quantia relativamente elevada para as circunstâncias socioeconómicas atuais, unicamente para poder ver-se implicado e atuar ativamente no processo penal.

Terceiro aspeto, em contradição com o que é anunciado no $n^{\circ} 4$ do $_{\operatorname{art}^{\circ}} n^{\circ} 67-a$ do CPP, “4 - Assistem à vítima os direitos de informação, de assistência, de proteção e de participação ativa no processo penal, previstos neste Código e no Estatuto da Vítima", a transposição não operacionalizou a anunciada "participação ativa" vendando-a pela figura da vítima-assistente, sem qualquer acessibilidade.

Quarto e último ponto a destacar, parece-nos por demais evidente que o novo estatuto da vítima não a investiu do caráter de sujeito processual penal no ordenamento jurídico português. Apesar de haver agora uma definição de vítima, a mesma encontra sobreposições com, por exemplo, a figura do "ofendido". O ideal seria que todo o CPP fosse revisto e viesse a sofrer reformulações profundas e totais. Tendo em conta, no entanto, a questão da celeridade processual mencionada por Figueiredo Dias por um lado e a proteção dos direitos dos cidadãos, neste caso das vítimas de crimes por outro, poderse-ia ter dado um passo no sentido de fazer emergir, eventualmente, um patamar intermédio de acesso tácito ao estatuto da vítima-assistente por parte das vítimas de crimes violentos. Na impossibilidade de uma revisão profunda do CPP, que as vítimas de crimes violentos (à semelhança de, após confirmadas por autoridade competente, poderem vir a receber o adiantamento que o Estado português lhes confere), pudessem também gozar de forma tácita e direta do estatuto de assistente sem para tal necessitarem de fazer qualquer pagamento ou requerimento, mantendo-se sempre acompanhadas de defensor que as elucidariam e acompanhariam em todo o processo à semelhança do que já fazem com arguidos. É que, esclareça-se, com esta reflexão e proposta não se pretende diminuir os direitos do arguido que o CPP tão bem defende. Pretende-se sim repor a justiça da génese do processo penal que só existe pelo facto de haver alguém que foi invadido na sua esfera privada por outrem que lhe causou um mal previsto e punido por 
lei. Apenas assim se concretizaria um pleno direito de acesso ao direito e à justiça, impedindo a dupla vitimização em consequência da atual estratificação de acessos em que apenas quem tem posses económicas, tem voz plena e aceite no processo penal.

\section{BIBLIOGRAFIA}

Coyle, Andrew (2008) "Managing Prison Overcrowding: a European Perspective" in Rencontre Européenne de Directeurs d'administration Pénitentiaire - Ministère de Justice. Paris, $\begin{array}{lllll}\text { França de julho de } & 11 \text { 2008, }\end{array}$ http://www.prisonstudies.org/sites/prisonstudies.org/files/resources/downloads/present ation1.pdf [12 de Fevereiro de 2015].

Figueiredo Dias, Jorge (1993) "Sobre os sujeitos processuais no novo código de Processo Penal”. O Novo Código de Processo Penal. CEJ. Almedina.

Guia, Maria João (2015). “Imigração, 'Crimigração', e Crime Violento. Os Reclusos Condenados e as Representações sobre Imigração e Crime". Tese de Doutoramento em Direito, Justiça e Cidadania no Século XXI. Universidade de Coimbra.

Pemberton, Antony and Groenhuijsen, Marc, Developing Victim's Rights within the European Union: Past, Present and Future (October 21, 2011). Acedido em SSRN: http://ssrn.com/abstract=1947236 or http://dx.doi.org/10.2139/ssrn.1947236 aos 10/11/2015.Decisão Quadro 2001/220/JAI do Conselho, de 15 de Março

Projeto "Protecting Victims' Rights in the EU: the theory and practice of diversity of treatment during the criminal trial" (2013) (JUST/2011/JPEN/AG/2919), coordenado pelo Centre for European Constitutional Law - Themistokles and Dimitris Tsatsos Foundation (www.cecl.gr) e o Institute for Advanced Legal Studies, School of Advanced Study, University of London in_http://www.victimsprotection.eu/index.php/2014-05-01-19-31$\underline{19 / j \mathrm{~d} / \text { viewcategory/40-pt-portugal }}$

FRA (2014) "Violência contra as mulheres: um inquérito à escala da União Europeia".

\section{LEIS E PROPOSTAS DE LEI}

Lei ${ }^{\circ}$ 130/2015 de 4 de Setembro 
Programa de Estocolmo (2009) "Uma Europa aberta e segura que sirva e proteja os cidadãos".

Tratado de Lisboa

Lei 112/2009, de 16 de Setembro - Lei da Violência doméstica.

Proposta de lei 343/XII/4a (GOV) de CSM, 2015.

Lei 83/2015, de 05 de Agosto.

Lei 93/99, de 14 de Julho - Lei de Proteção de testemunhas.

Lei 21/2007, de 12 de Junho - Criação de um regime de mediação Penal.

Lei n. ${ }^{\circ}$ 104/2009, de 14 de Setembro - Regime de concessão de indemnização às vítimas de crimes violentos e de violência doméstica.

Lei 23/2007, de 4 de Julho - Lei de estrangeiros

Decreto-Regulamentar 368/2007, de 5 de Novembro - Regulamentação de concessão de autorização de residência a vítimas de tráfico de pessoas.

Decreto-Lei ${ }^{\circ}$ 78/87, de 17 de Fevereiro, 2015.

Tratado de Funcionamento da União Europeia.

EUROPEAN COMMISSION, DG JUSTICE, Dezembro 2013.

Parecer sobre a Proposta de Lei no 343/XII/4a (GOV), datado de 03/07/2015, elaborado pelo adjunto do GAVPM, Juiz de Direito, Dr. Carlos Gabriel Donoso Castelo Branco.

Proposta de lei 343/XII/4a (GOV)

\section{OUTRA BIBLIOGRAFIA}

Comunicação intitulada "Thoughts and hopes for victims' rights in the future", ocorrida no passado dia 14/01/2016, no Seminário IVOR organizado pela APAV, Katazyna Janicka-Pawlowska da Comissão Europeia 